\title{
THE NATURE OF BARRED OWL DAYTIME ROOST SITES IN SASKATCHEWAN
}

KURT M. MAZUR, Manitoba Conservation, Box 24, 200 Saulteaux Cres., Winnipeg, MB R3J 3W3, SHANNA D. FRITH, Box 273, Balmoral, MB ROC OHO, and PAUL C. JAMES, Saskatchewan Environment and Resource Management, 3211 Albert St., Regina, SK S4S 5W6.

The Barred Owl has long been considered an owl of "deep, dark woods", inhabiting heavily wooded areas including swamps and upland forests. ${ }^{2,6}$ Numerous accounts of Barred Owls from the southern and eastern part of its range confirm this bird's preference for concealing roost sites in densely foliated coniferous and deciduous trees. ${ }^{1,4,5,9}$ The use of such sites would presumably provide protection from mobbing birds, as well as protection from cold. Barred Owl roost sites are also reported to be used repeatedly, as indicated by numerous pellets and whitewash below. ${ }^{1,9} \mathrm{We}$ compare our observations of Barred Owl roost sites in the southern boreal forest of central Saskatchewan with these aspects of the traditional description of roost sites.

We marked 15 adult Barred Owls with radio transmitters in Prince Albert National Park and the adjacent Prince Albert Model Forest, Saskatchewan. ${ }^{7}$ On 64 walk-in visits throughout 1993 and 1994, during daylight hours, we located radio-marked owls and made note of their daytime roost tree. When we walked to owl roost sites, more often than not, the owl would fly from

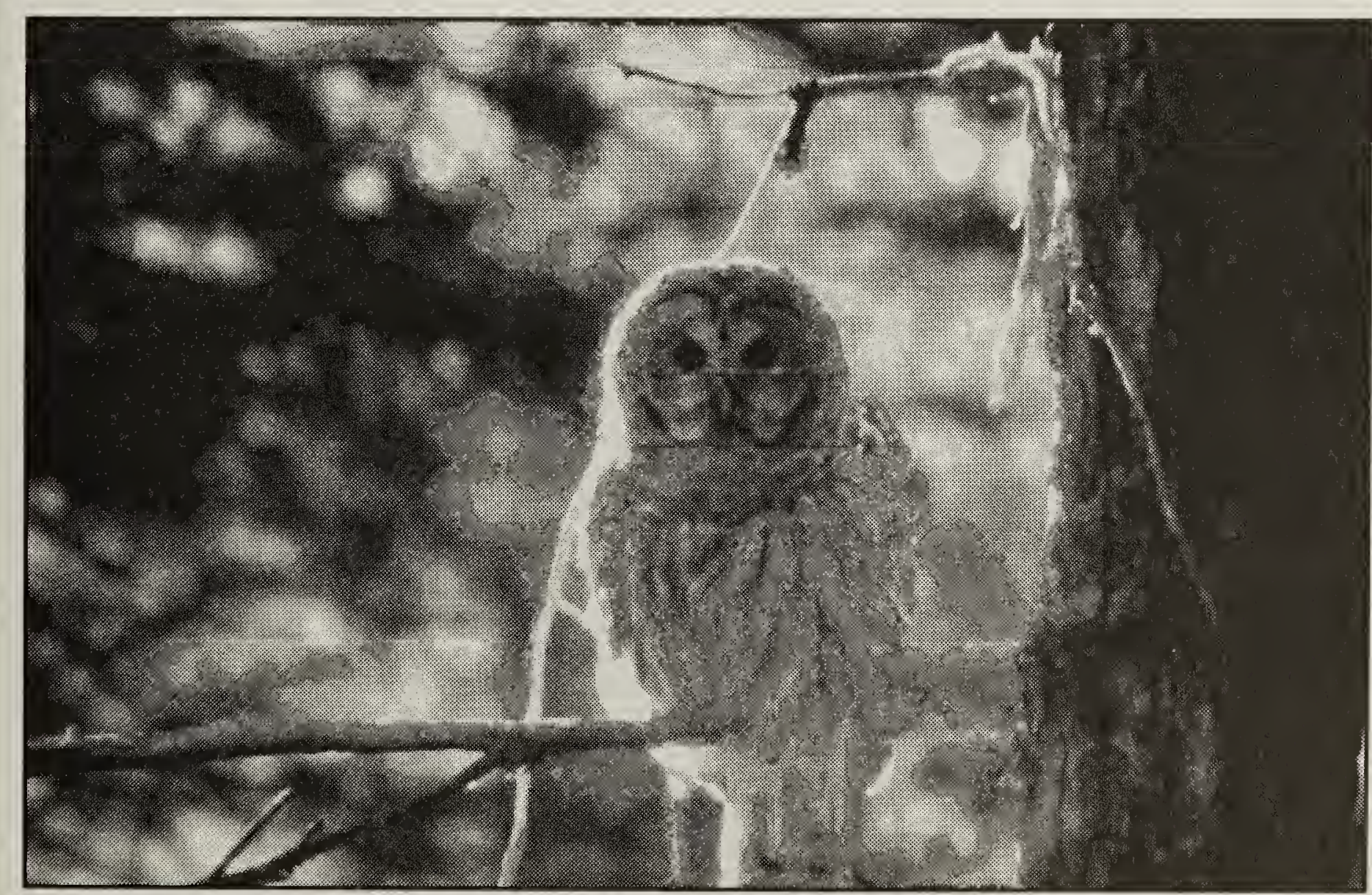


its roost before we spotted it. Flight was evident from the radio signal which fluctuated from its normal even beep. On the 64 walk-in visits we observed only 16 roost sites of 9 individual owls. The other 6 owls continually flew before we were able to see them on their roost.

All 16 roost sites were in mixedwood stands (a combination of deciduous and coniferous tree species). We observed 11 roosts in deciduous trees: Trembling Aspen (Populus tremuloides), Balsam Poplar (Populus balsamifera) and Paper Birch (Betula papyrifera), and 5 in coniferous trees: White Spruce (Picea glauca), Black Spruce (Picea mariana) and Jack Pine (Pinus banksiana) (Table 1). This suggests that Barred Owls in the southern boreal forest of Saskatchewan do not select thick cover for roosting. During winter, we did observe owls roosting in coniferous trees, but they roosted as often in leafless Trembling Aspen that offered little thermal protection. Perhaps the owls were exposing themselves to the sun for thermal gain. In summer, we also observed owls in both coniferous and deciduous trees. On a number of occasions owls were perched very high in Trembling' Aspen, just below the canopy. Perhaps the owls were roosting in the shade of the canopy but high enough to catch the breeze. Our observations are similar to those of Barred Owl roost sites in the foothills of Alberta, where 19 of 25 roost sites were in deciduous trees (11 Trembling Aspen, 8 Balsam Poplar), and 6 in coniferous trees (White Spruce). ${ }^{8}$

We did not observe pellets and whitewash at roosting sites and concluded that the owls did not use the same site repeatedly, as has been reported by others. ${ }^{1,9}$ Our radio telemetry data indicate that Barred Owls roosted in the area in which they were observed hunting the previous night, and often moved to a new area the following night to hunt. Spotted Owls in Oregon also have been observed to roost in the area last hunted. ${ }^{3}$ In the boreal forest of Saskatchewan, Barred Owl home ranges in winter are, on average, six times larger than those found in the eastern and southern part of the species range. ${ }^{7}$ With such a large home range,

Table 1. Roost trees of nine individual Barred Owls in the boreal forest of central Saskatchewan.

\section{Tree Species}

$\begin{array}{ll} & \text { Summer } \\ \text { White Spruce } & 1 \\ \text { Black Spruce } & 1 \\ \text { Jack Pine } & -\end{array}$

Total Coniferous

Trembling Aspen

Balsam Poplar

White Birch

Total Deciduous

TOTAL
2

5

2

$-$

7

9

\section{\# Roost Sites per Season}

Winter
2
-
1
3

3

3

$-$

1

4

7
Total

3

1

1

5

8

2

1

11

16 
repeated use of particular roost sites may not be energetically advantageous. Summer home ranges in Saskatchewan, however, are similar in size to those reported elsewhere; yet even in this season, Barred Owls did not use roost sites repeatedly.

The fact that in 46 out of 64 instances, owls flew before we could see them, and that we were unable to observe roosting sites for 6 of 15 radio-marked owls, suggests a large degree of shyness towards people. This avoidance of people is considered typical for the Barred Owl, as it generally inhabits heavily forested areas away from human activity. However, we observed some individual owls that were remarkably bold, allowing us to approach closely. These bold owls also nested in close proximity to human residences, suggesting that they were habituated to people.

\section{Acknowledgements}

Funding and support for this project was provided by the Prince Albert Model Forest, Saskatchewan Heritage Foundation, Wildlife Development Fund, Prince Albert National Park, Nature Saskatchewan, and the Northern Forest Owl Symposium Research Award. Comments by Robert Nero and one anonymous reviewer greatly improved this article and are much appreciated.

1. Applegate, R.D. 1975. Co-roosting of Barred Owls and Common Grackles. Bird-banding 46:169-170.
2. Bent, A.C. 1938. Northern Barred Owl. In Life Histories of North American Birds of Prey. Part II. Dover Publishing Inc., New York .

3. Carey, A.B., S.P. Horton, and J.A. Reid. 1989. Optimal sampling for radiotelemetry studies of Spotted Owl habitat and home range. Research Paper PNW-RP-416, Portland, OR. 17 pp.

4. Elody, B.I., and N.F. Sloan. 1985. Movements and habitat use of Barred Owls in the Huron Mountains of Marquette County, Michigan, as determined by radiotelemetry. JackPine Warbler 63:3-8.

5. Jackson, L.S., C.A. Thompson, and J.J. Dinsmore. 1996. The lowa Breeding Bird Atlas. University of lowa Press, lowa City, IA.

6. Johnsgard, P.A. 1988. North American Owls. Smithsonian Institution Press, Washington, DC.

7. Mazur, K.M., S.D. Frith, and P.C. James. 1998. Barred Owl home range and habitat selection in the boreal forest of central Saskatchewan. Auk 115:746754.

8. Takats, D.L. 1998. Barred Owl Habitat Use and Distribution in the Foothills Model Forest. Master's thesis, University of Alberta, Edmonton, AB. 139 pp.

9. Wilson, K.A. 1938. Owl studies at Ann Arbor, Michigan. Auk 55: 187-197.

"In order to stand in the right relation to wilderness, one must stand in the right relation to civilization". Evan Eisenberg, The Ecology of Eden p. xvi 